\title{
50 Anos de Psicologia no Brasil: A Construção Social de uma Profissão
}

50 Years of Psychology in Brazil: The Social

Construction of a Profession

50 Anos de psicología en brasil: la construcción social de una profesión

Odair Furtado

Pontifícia

Universidade Católica de São Paulo

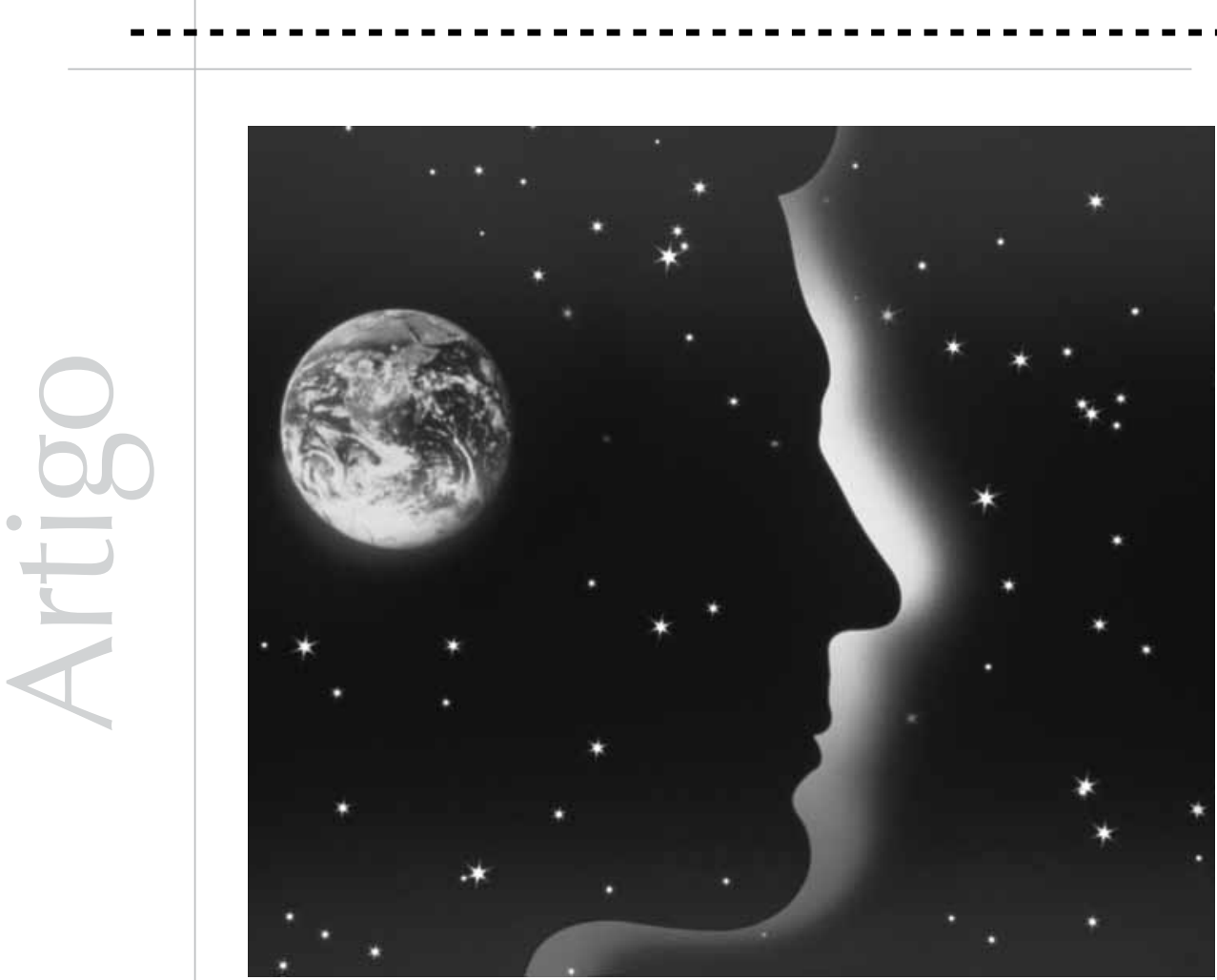


Resumo: As profissões imperiais, assim Edmundo Campos Coelho, um sociólogo das profissões, designa as profissões (engenheiro, médico e advogado) que se constituíram e foram as primeiras a ganhar regulamentação a partir de 1822, primórdios da fase imperial brasileira e momento que marca o início da institucionalização e do regramento da vida dos brasileiros depois da ruptura com a metrópole colonial. Interessa-nos essa análise na medida em que nos ajuda a compreender como a Psicologia constituiu a sua própria institucionalização e como ela encontra espaço social para avançar como profissão considerada necessária e importante para os diversos campos em que atua. Nenhuma profissão sobrevive se não é considerada socialmente relevante e demandada pela população. Desse ponto de vista, qual a importância social da Psicologia e qual seu futuro imediato no Brasil, considerando que estamos ultrapassando a barreira dos 200 mil psicólogos com registro no sistema Conselhos de Psicologia (aptos a atuarem profissionalmente)? Isso significa que atingimos o padrão de cobertura considerado adequado pela Organização Mundial de Saúde para a nossa população. Temos psicólogos suficientes para garantir o atendimento psicológico em todos os segmentos da saúde, do trabalho, da educação, da Justiça, dos meios de comunicação e de tantas outras áreas em que hoje esse profissional está inserido. Essa condição é suficiente para o que pretende a profissão, considerando as ações das entidades de classe? A população foco dos serviços prestados reconhece o valor dessa profissão? São questões que indicam a condição organizativa em que nos encontramos hoje, cinquenta anos depois da regulamentação da profissão. Esse patamar de nossa organização e de nossa atividade profissional é indicativo de maturidade do campo profissional e, ao mesmo tempo, indicativo de que há muito a se construir. Diz a música popular que, "se muito vale o que foi feito, mais vale o que virá". O que nos reserva esse futuro e qual a potência dessa profissão é o que discutiremos a seguir. Palavras-chave: História da Psicologia - Brasil. 50 anos da Psicologia . Atuação do Psicólogo.

Abstract: The imperial occupations, this is the way Edmundo Campos Coelho, a sociologist, names the occupations (engineer, doctor and lawyer) that were constituted and that were the first ones to be regulated from 1822 on, in the beginning of the Brazilian imperial period and the regulation of the Brazilian's life after the political rupture with the metropolis. This analysis interests us for it helps us to understand how psychology constituted its own institutionalization and how it finds social space to advance as an occupation which is considered important and necessary for the many fields in which it is put into action. No occupation can survive if it is not considered socially relevant and required by the population. From this point of view, what's the social importance of psychology and what is its immediate future in Brazil, considering that we are now surpassing the number of 200 thousand psychologists who are registered in the Federal Psychology Council (who are able to work)? That means that we have reached the amount of attendance the World Health Organization considers appropriated for our population. We have enough psychologists to attend our population in the health, work, education, justice, media and in so many other areas where this professional is required. Is this enough for what the class entities of the occupation intend? The population who is attended recognizes the importance of the occupation? These subjects indicate the organizative condition we have today, 50 years after the regulamentation of the occupation. This level of organization and work indicates the maturity of the professional field and also that there is a lot to build. There's a song that says that "if it is worthwhile what has been done, it's more valuable what will come". We'll discuss now what the future will bring us and what is the efficiency of this occupatio Keywords: History of psychology. 50 years of psychology. Social construction of psychology.

Resumen: Las profesiones imperiales, así Edmundo Campos Coelho, un sociólogo de las profesiones, designa las profesiones (ingeniero, médico y abogado) que se constituyeron y fueron las primeras a ser reglamentadas a partir de 1822, a principios de la fase imperial brasileña y momento que marca el inicio de la institucionalización y del reglamento de la vida de los brasileños después de la ruptura con la metrópolis colonial. Nos interesa ese análisis en la medida en que nos ayuda a comprender cómo la Psicología constituye su propia institucionalización y cómo ella encuentra espacio social para avanzar como profesión considerada necesaria e importante para los diversos campos en que actúa. Ninguna profesión sobrevive si no es considerada socialmente relevante y demandada por la población. Desde ese punto de vista, ¿̇uál es la importancia social de la Psicología y cuál es su futuro inmediato en el Brasil, considerando que estamos ultrapasando la barrera de los 200 mil psicólogos con registro en el sistema de Consejos de Psicología (aptos a actuar profesionalmente)? Eso significa que alcanzamos el estándar de cobertura considerado adecuado por la Organización Mundial de la Salud para nuestra población. Tenemos psicólogos suficientes para garantizar el atendimiento psicológico en todos los segmentos de la salud, del trabajo, de la educación, de la Justicia, de los medios de comunicación y de tantas otras áreas en que hoy ese profesional está inserido. ¿Es esa condición suficiente para lo que pretende la profesión, considerando las acciones de las entidades de clase? ¿Reconoce la población foco de los servicios prestados el valor de esa profesión? Son cuestiones que indican la condición organizativa en que nos encontramos hoy, cincuenta años después de la reglamentación de la profesión. Ese nivel de nuestra organización y de nuestra actividad profesional es indicativo de madurez del campo profesional y, al mismo tiempo, indicativo de que hay mucho a ser construido. Dice la música popular que, "si mucho vale lo que fue hecho, más vale lo que vendrá". Lo que nos reserva ese futuro y cuál la potencia de esa profesión es lo que discutiremos a seguir.

Palabras clave: Historia de la Psicología. Cincuenta años de la Psicología. Construcción social de la Psicología. Dimensiones subjetivas de la realidad. 
Comemoramos, em 2012, os cinquenta anos da regulamentação da Psicologia no Brasil. É dispensável dizer que a Psicologia brasileira não começou nessa data, a da promulgação da lei, e que ela é uma profissão centenária. Também é dispensável dizer que não há um locus fundador, um início retumbante, mas um processo que se instala lenta e gradualmente, conforme as exigências sociais e as confluências de novos e velhos saberes, descobertas, oportunidades. Os historiadores da Psicologia brasileira, particularmente Massimi (1986, 1990, 1999) e Antunes (1999, 2004), defendem a tese de que havia no Brasil um saber psicológico antes da chegada da Psicologia científica como elaborada em solo europeu. Podemos exagerar essa tese afirmando que havia um saber psicológico mesmo antes da chegada do colonizador. Evidentemente, garantidas todas a ressalvas de cunho cultural e antropológico, havia um saber psicológico entre os tupis-guaranis que nada tinha a ver com a Psicologia europeia, mas que tratava da compreensão da subjetividade dos povos que habitavam estas terras antes da ocupação do solo brasileiro pelos portugueses, um saber que não foi registrado e que nos chega através dos povos remanescentes e das peculiaridades presentes em nossa cultura, uma cultura negra, indígena e branca europeia, que hoje conta com a contribuição dos imigrantes europeus e asiáticos.

No Brasil se dá um processo diferente do ocorrido no México, no Peru e na Bolívia, para citar locais que também foram ocupados e colonizados. Nesses, a população indígena passou a fazer parte, de maneira significativa, da composição étnica da população, e os saberes dessas culturas foram integrados de forma mais sistemática e constante do que no caso brasileiro. Perdemos essa riqueza e não sabemos como identificá-la, claramente, na nossa cultura, assim, resta às nossas historiadoras buscar referência na produção intelectual registrada durante o período colonial.
A organização tardia das profissões universitárias, dadas as condições em que era mantida a colônia pelo império português, é responsável direta pelo atraso do desenvolvimento de massa crítica em solo brasileiro. Somente os filhos dos colonizadores aqui residentes, e os mais ricos, tinham alguma possibilidade de estudos mais avançados, e, mesmo assim, em Portugal ou em outros países europeus. Foi a transferência da sede da corte portuguesa, em 1808, para o Brasil o fato que alterou rápida e profundamente essa realidade. Na condição de nova sede da monarquia portuguesa, foi necessária uma mudança radical na política de colonização exercida por Portugal no Brasil, que era de exploração da riqueza natural e de uso da agricultura. Havia a proibição do estabelecimento da imprensa (não se permitia a impressão de livros), a proibição da instalação de indústrias em solo brasileiro e uma condição precária de educação (os jesuítas foram os responsáveis pelo ensino desde 1549, e construíram uma base considerável formando professores e especializando o ensino, criando o embrião do que hoje conhecemos como faculdades, mas, com a sua expulsão pelo Marquês de Pombal, em 1759, o ensino no Brasil entra em colapso). Três histórias de personalidades desse período nascidas em solo brasileiro são bem ilustrativas do percurso daqueles que conseguiam escapar do analfabetismo que atingia $70 \%$ da população e que reuniam recursos suficientes para ir a Portugal ou para outros países europeus completar seus estudos.

Um caso bastante emblemático é o de José da Silva Lisboa, o Visconde de Cairu. De acordo com Rocha (2001), Lisboa era filho de um construtor vindo de Portugal para Salvador, na Bahia, que havia conseguido enviar os filhos para estudar na Universidade de Coimbra, em Portugal, e o filho José formou-se em letras, voltando ao Brasil logo em seguida. Em Salvador, passou a ministrar aulas de Filosofia 
Os portugueses estavam aqui de passagem, e os nascidos aqui, os nativos e os africanos escravizados, eram,

deliberadamente, mantidos em condições precárias, tratados com desconfiança, sem acesso a qualquer tipo de regalia da nascente modernidade burguesa.

Considerando a pequena densidade demográfica, 12 milhões de habitantes em 1884 (Weffort, 2006), o País era tido como "uma nação sem povo".
Racional e Moral de 1779 a 1797. No final do seu período docente, ainda de acordo com Rocha, ele entra em contato com a obra de Adam Smith A Riqueza das Nações, e encanta-se com a visão liberal do autor, que o inspira a escrever dois livros que serão publicados em Portugal. Certamente, foi o Visconde de Cairu o primeiro brasileiros a ocupar-se de Economia política, uma área nascente da Economia na Europa, e, adepto da visão liberal, influenciou a decisão do príncipe regente na abertura dos portos brasileiros ao livre comércio.

Outro caso é o de Hipólito José da Costa. Filho de militar, nasceu em 1774, durante a ocupação da Colônia de Sacramento (Uruguai), e viveu em Porto Alegre, onde realizou seus estudos iniciais. Foi enviado para Portugal, em 1793, para estudar na Universidade de Coimbra. De acordo com Paula (2001), Hipólito não volta mais ao Brasil, mas é o fundador do primeiro jornal brasileiro, o Correio Braziliense, editado em Londres e escrito em português. Paula relata a forte influência exercida por esse jornal não somente na corte portuguesa, onde encontrava leitores qualificados, como na própria colônia, onde chegava pelo correio marítimo depois de longa viagem. Hipólito era o único redator do periódico, e manteve o jornal funcionando de 1808 a 1822, ano da sua morte.

O terceiro caso, mais emblemático ainda, é o de José Bonifácio de Andrada e Silva, conhecido como Patriarca da Independência do Brasil. Nascido em 1763, em Santos, filho de família aristocrática portuguesa, também estudou em Coimbra, tendo desenvolvido sua carreira em Portugal e viajado e estudado em vários países da Europa. Ministrou aulas em Coimbra sobre mineralogia e trabalhou nessa área para a coroa portuguesa até o seu retorno ao Brasil, em 1819. José Bonifácio teve enorme importância na constituição do Império brasileiro, pois influenciou o reinado de Pedro I e participou da fase inicial do reinado de Pedro II. Na coleção de obras denominadas Projetos para o Brasil (1998), podemos ter ideia da formulação de um pensamento organizado e inspirado pelo iluminismo francês, que projetava um Brasil independente.

Trata-se de um conservador e de dois liberais que tiveram, ao seu modo, importância na transição para a constituição de um governo brasileiro, o Primeiro Império, e que eram esclarecidos o suficiente para considerar as condições de um Brasil independente. As histórias pessoais demonstram as condições precárias da colônia e o modo português de exploração econômica. Os portugueses estavam aqui de passagem, e os nascidos aqui, os nativos e os africanos escravizados, eram, deliberadamente, mantidos em condições precárias, tratados com desconfiança, sem acesso a qualquer tipo de regalia da nascente modernidade burguesa. Considerando a pequena densidade demográfica, 12 milhões de habitantes em 1884 (Weffort, 2006), o País era tido como "uma nação sem povo".

Parte dessa condição precária é fruto da decadência vivida pelos ibéricos após a fase de apogeu representada pela ocupação das colônias ultramarinas e pelo domínio da navegação de longa distância. Assim se expressa Weffort, citando Richard Morse:

... As colônias anglo-saxônicas e ibéricas foram, em seu tempo, duas 'opções' de entrada do mundo para a modernidade. Formadas em um longo período que se estende do século XII ao XVII, essas duas tradições, a ibérica e a anglo-saxônica, teriam surgido 'de uma matriz moral, intelectual e espiritual comum' (2006, p.20)

Ainda de acordo com o autor, os ventos da contrarreforma e o esgotamento do modelo colonial-expansionista levaram o modelo ao esgotamento. "Embora Portugal e Espanha tenham descoberto e inaugurado o Novo Mundo, estavam condenados a 
ser países menores, pouco mais do que entrepostos da nova etapa comercial do desenvolvimento capitalista europeu. Os efeitos dos vícios de origem permaneceriam por muito tempo como um entrave cultural para o desenvolvimento dos países iberoamericanos" (Weffort, 2006, p.27). Mesmo assim, por condições peculiares, a América espanhola avançou mais que a América portuguesa. Continuando com a análise de Weffort, falando de Portugal:

Além da intolerância religiosa, havia a ganância aventureira de riquezas e poder por parte da nobreza, e uma mentalidade medieval incapaz de entender a iniciativa que visa ao lucro. Desse modo, as atividades capitalistas e artesanais tendiam a ser monopolizadas por grupos relativamente fechados - além dos 'cristãos-novos', os estrangeiros, sobretudo ingleses, franceses e holandeses - que legal ou ilegalmente faziam em Lisboa ou em Sevilha boa parte do comércio externo peninsular (2006, p.26)

São essas as condições materiais, econômicas, políticas e culturais que encontramos no Brasil na época de sua independência. E são elas que irão orientar a construção do Estadonação brasileiro. Parte da precariedade, como já apontamos, foi superada pela transferência da corte portuguesa para o Brasil em 1808. Sem a alternativa de Coimbra ou de outras universidades europeias, foi necessário abrir condições imediatas para a elite portuguesa instalada no Brasil continuar usufruindo de suas benesses. Foi assim que nasceu o curso de Medicina e o de Engenharia, e, logo depois, já no período imperial brasileiro, os cursos de Direito. Mais adiante, a escola de Belas-Artes complementa o circuito da possibilidade de formação universitária em solo brasileiro. A abertura dos portos e a liberação da imprensa garantem o futuro contato com o mundo. Nesse momento, podemos dizer, nascem as profissões universitárias brasileiras, de forma inconsistente, precária, elitizada e que ainda dependiam da formação de seus melhores quadros no exterior.Continuamos sem autonomia científica, sem política de Estado e dependentes das figuras da elite e de sua vontade de melhorar as condições de vida dos brasileiros, que engatinhavam na constituição de um povo que, na época, era segmentado entre os não cidadãos (negros escravizados e índios) e os pobres (libertos, mestiços e brancos que não estavam ligados às elites).

A menção aos fatos históricos que determinam o aparecimento e o desenvolvimento das profissões universitárias no Brasil não representa intenção diletante ou viés historicista, mas demarca que a origem dessas profissões tem forte apelo elitista e desenvolve-se em um ambiente em que essa elite é precária e dependente de sua matriz, principalmente de Portugal, mas, prioritariamente, da Europa culta e desenvolvida.

O final do século XVIII e o decorrer do século XIX testemunharam, em solo europeu, um grande avanço do modo burguês de organização do Estado, e a instalação da república burguesa, com seus princípios de um Estado protetor e distributivo (mesmo considerando a exploração de classes do nascente capitalismo como forma de acumulação de riqueza), propiciou real avanço das ciências e organizou as profissões científicas e universitárias. É curioso pensar que o Brasil, situado na periferia do mundo nessa época, com reais dificuldades de acesso, que era deficiente, demorado e perigoso (se a embarcação não naufragasse em uma tormenta, se não fosse abordada por piratas e se não fosse atingida pelo escorbuto, chegava-se ao destino!) e com precárias condições de vida (o Rio de Janeiro era uma cidade insalubre, e São Paulo, uma vilazinha que servia de entreposto para os viajantes que vinham de Santos/São Vicente), estivesse em contato com os avanços da ciência moderna. Mas isso acontecia, e a 
1Veja a análise que Michel Foucault faz do desenvolvimento da Medicina e das formas de apropriação do corpo humano pelas ciências médicas: "... No início do século XIX, os médicos descreveram o que, durante séculos, permanecera abaixo do limiar do visível e do enunciável. Isso não significa que, depois de especular durante muito tempo, eles tenham recomeçado a perceber ou a escutar mais a razão do que a imaginação, mas que a relação entre o visível e o invisível, necessária a todo saber concreto, mudou de estrutura e fez aparecer, sob o olhar e na linguagem, o que se encontrava aquém e além de seu domínio..."

(Foucault, Nascimento da Clínica, 1980, prefácio, pág. X).

2 Para aprofundar essa questão, veja Furtado (2011) em Trabalho e solidariedade. demora nas comunicações não era empecilho para a chegada do modelo europeu de organização e de institucionalização do saber ${ }^{1}$. A aplicação das ideias liberais de Adam Smith pelo Visconde de Cairu na incipiente administração pública brasileira nos mostra como isso era possível, em um misto de ousadia e precariedade, precariedade pela falta de um modelo a substituir, pela forma distorcida como foi apresentada ao Visconde a obra A Riqueza das Nações e pela ousadia de buscar o novo no lugar imponderável. Com a criação dos cursos superiores de Medicina, Engenharia e Direito, esse comportamento ousado se ampliou, e novos personagens aparecem no cenário das recém-inauguradas ciências brasileiras, evidentemente, fruto da nascente organização do Estado brasileiro e da consolidação do Império e do governo de D. Pedro II.

\section{O surgimento das profissões no Brasil}

Vimos que o quadro de precariedade do Brasil colônia e a dura transição para uma ordem instituída que vai da nossa Independência até o fim da Primeira República (a República Velha que se encerra com a revolução de 1930) não colaborava para garantir ao Brasil as condições estruturais necessárias para o seu desenvolvimento. Tudo aqui chegou tardiamente: a industrialização, a formação, o saneamento. Sintetizando, a organização capitalista não vicejava nestas plagas, a despeito de termos servido para o acúmulo de riqueza que a produziu na Europa e de termos aparecido sob o signo da modernidade (não havia feudalismo no Brasil). Assim, nossas profissões aparecem como ocupações, demandadas pela necessidade, com o desenvolvimento urbano de Salvador, do Rio de Janeiro e de Ouro Preto. O enriquecimento das famílias nobres que exploravam a agricultura, a pecuária e a mineração passou a exigir um padrão mais sofisticado de vida, e foi preciso trazer artesãos especializados em construção e buscar o desenvolvimento de materiais compatíveis com o tipo de arquitetura ibérica. O enriquecimento dessas famílias e da Igreja Católica levou à construção de igrejas mais suntuosas, e isso propiciou o desenvolvimento da arte sacra e a formação de artistas brasileiros, como foi o caso de Aleijadinho. A edificação, a metalurgia, o ramo têxtil e a indústria de alimentos eram setores que exigiam gente especializada e que definiam a ocupação para um segmento social que não era escravizado e não era nobre. Organizava-se um campo de profissionalização através das ocupações que se realizavam no cotidiano das cidades.

Até hoje vemos, no campo brasileiro, a prática da construção com paredes de barro. São as casinhas de pau a pique, construídas pelos nossos sertanejos, que são feitas a partir de madeira fina e roliça recolhida no mato, de barro amassado e de palha. Esse tipo de construção é confeccionado pelo próprio morador, e não exige a contratação ou a ajuda de pessoal especializado. Os casarões coloniais do centro do Rio de Janeiro, do Pelourinho, em Salvador, e do complexo urbanístico de Ouro Preto são muito sofisticados e exigem pessoal muito qualificado para a sua construção, qualificação e saber constituídos até aquele momento que estavam concentrados na figura do artesão, do prático em construções que se ocupava desse serviço, que foi trazido de Portugal e que aqui ensinou a brasileiros o ofício; ofício e ocupação, assim nascem as profissões entre nós.

Evidentemente, nossa elite, carente de um status maior que permitisse compará-la à aristocracia europeia, não se deixaria confundir com uma dimensão de trabalho que as remetesse ao nível do fazer cotidiano. ${ }^{2}$ Assim, as profissões de formação universitária passam a ser chamadas, aqui no Brasil, de 
3 De acordo com a historiadora Márcia Regina Barros da Silva (2010), as Santas Casas de Misericórdia estão presentes no Brasil desde o período colonial. A Santa Casa do Rio de Janeiro foi montada pelo Padre José de Anchieta, e já existia a Santa Casa em São Paulo e

Salvador. Entretanto, tratava-se de lugar de recolhimento dos doentes, e não exatamente de um hospital. Segundo a historiadora, na Santa Casa de São

Paulo, no ano 1872, havia um único médico contratado: o doutor Antônio Caetano de Campos. $\mathrm{Na}$ Santa Casa de Misericórdia de São Paulo, saúde e assistência se tornam públicas (1875-1910). profissão e logo depois de profissões liberais, e as que não exigem formação universitária e são adquiridas na prática do ofício passam a ser designadas de ocupação. Edmundo Campos Coelho faz uma boa discussão sobre isso, apoiado em argumentos do sociólogo Wanderley Guilherme dos Santos. Para o autor, nada separa o termo profissão de ocupação, entretanto, no Brasil, destinouse o termo ocupação para as atividades consideradas subalternas, e profissão para aquelas atividades que exigiam curso superior e que passavam por regulamentação do Estado. De acordo com o autor, em 1838, com o Império bem instalado, ainda não havia um mercado liberal para médicos, engenheiros e advogados. A população da cidade do Rio de Janeiro, metrópole e capital do Império, "era 'feia e suja', segundo todos os cronistas da época... os escravos eram 38\% da população" (1999, p. 72). Assim, não havia cidadãos em condições de pagar consultas que mantivessem um mercado consistente para esses profissionais. ${ }^{3}$ Os demais, com baixa renda ou sem renda nenhuma, caso dos escravos, simplesmente não eram atendidos. Somente a partir de 1870 , com as melhorias urbanas instaladas na cidade do Rio de Janeiro e nas capitais de províncias, é que essa história se transforma, essas profissões conquistam seu mercado e seus integrantes passam a ter rendimento de destaque, consolidando o status que mantêm até os dias de hoje.

Essa é a nossa matriz profissional, tanto do ponto de vista econômico, a partir da venda de serviços de forma liberal - que significa diretamente ao público interessado - ou na forma assalariada - como ocorreu principalmente com os engenheiros e também com os advogados e com os médicos - quanto do ponto de vista do prestígio, na forma como subjetivamente as profissões são valorizadas socialmente. Nesse ponto, são as relações sociais e as formas de troca simbólica entre extratos da população que demarcam diferenças de classes não apenas a partir da relação com a produção mas também a partir do modo de vida, e que, de acordo com Bourdieu (2007), garantem a constituição de habitus que indicam o que o autor denomina distinção, e que temos trabalhado como dimensões subjetivas da realidade (Furtado, 2002, 2011; Furtado \& Svartman, 2009). Para melhor explicitar essa posição de Bourdieu, importante para a avaliação do caminho subjetivo percorrido pelas profissões liberais no Brasil, citamos o próprio autor:

Ocorre que só pode haver uma verdadeira compreensão das diferenças, às vezes imensas, que separam categorias, apesar de sua proximidade no espaço objetivo - tais como os artesãos ou os agricultores e os contramestres ou os técnicos -, se for levada em consideração, além do volume e da estrutura do capital, a evolução no tempo dessas propriedades, ou seja, a trajetória social do grupo em seu conjunto e do indivíduo considerado e de sua linhagem, que se encontra na origem da representação subjetiva da posição objetivamente ocupada. Uma das características mais determinantes das escolhas políticas reside, efetivamente, no fato de que elas fazem intervir, mais que todas as outras escolhas - mais, sobretudo, que as escolhas obscuras e profundas do habitus -, a representação mais ou menos explícita e sistemática que o indivíduo tem do mundo social, assim como da posição que ocupa e 'deveria' ocupar nele, e o discurso político, quando existe enquanto tal, limita-se a ser, na maior parte das vezes, a expressão mais ou menos eufemizada e universalizada - e sempre irreconhecível para quem o pronuncia - dessa representação" (Bourdieu 2007, p.424) (grifos do autor no original).

Devo esclarecer que Bourdieu não está analisando o fenômeno das profissões na citação acima, e sim, o fenômeno da escolha política a partir de representações construídas através de determinadas posições sociais 
4 É precioso o livro organizado por Mitsuko Antunes (2004), História da Psicologia no Brasil: primeiros ensaios, no qual são reproduzidos artigos dos pioneiros da Psicologia e de seus primeiros historiadores. É o caso dos dois artigos de Isaías Pessotti, Dados para uma História da Psicologia

no Brasil (1975) e Notas para uma História da Psicologia no Brasil (1988), que nos serviram imensamente na elaboração dessa análise. assumidas pelos atores; ademais, sua análise refere-se não somente a uma condição contemporânea, como ele fala de como esse fenômeno ocorre na França nos anos 70. Entretanto, interessa-nos como o autor trabalha a dimensão subjetiva (mesmo não acompanhando o autor em suas referências analíticas), que nos serve para apontar, a partir da definição do valor da profissão liberal no Brasil, a posição que ocupam essas profissões nos dias atuais e como mantêm entre si a hierarquia que notamos nas disputas de mercado e de prestígio social. Veja o que ocorre com a Arquitetura e a Engenharia e, principalmente, com os valores que mobilizam toda a disputa promovida pelo projeto de lei conhecido como Ato Médico. Como se ainda vivêssemos no período imperial, a corporação médica busca, até o momento infrutiferamente, estabelecer uma hierarquia entre a Medicina e as demais profissões da saúde, exigindo que as pessoas que buscam atendimento em uma delas passem inicialmente pelo diagnóstico médico. Consideram que somente o médico está habilitado para realizar um diagnóstico no campo da saúde; do que se trata, a não ser de manutenção do prestígio adquirido socialmente pelos médicos (e que não está adaptado aos modos atuais das práticas profissionais) e da proteção corporativa do mercado de trabalho na forma de reserva obrigatória de cargos e funções?

O fato é que nos referimos à matriz que produziu o valor agregado à posição social das chamadas profissões imperiais - médico, engenheiro e advogado - no curso da constituição da ordem social brasileira. O desenvolvimento social das demais profissões universitárias seguiu essa mesma matriz, mas encontrou um mundo, pode-se dizer, mais profissionalizado, mais organizado do ponto de vista das atividades desenvolvidas pelos profissionais das diferentes ocupações socialmente definidas. Aqui se encontra, entre outras, a Psicologia.

\section{A Psicologia como profissão}

A despeito de todo o rigor histórico presente nas publicações sobre a presença da Psicologia no Brasil e de alentada discussão sobre o que seria seu momento inicial, vamos considerar que o desenvolvimento da área como ciência e profissão deve muito à organização do campo universitário. A formação sistemática de quadros nas faculdades de Filosofia, Ciências e Letras do Rio de Janeiro, Belo Horizonte, São Paulo e Recife (entre os principais centros de formação) e o desenvolvimento de pesquisas e de divulgação das correntes e das teorias desenvolvidas nos principais centros produtores de conhecimento na primeira metade do século XX foram decisivos para a construção e a divulgação do saber e da prática psicológica. ${ }^{4}$

Já vimos aqui mesmo e sabemos que esse campo universitário foi organizado tardiamente, mas quando organizado (considerando que as primeiras universidades passaram a funcionar a partir de 1930), apropriou-se do que havia de mais avançado e desenvolvido nas universidades americanas e europeias. Além do mais, temos quadros experimentados formados na Filosofia, na educação e na Medicina que se interessam pelo fenômeno psicológico e constroem essa atividade profissional; temos, ainda, a demanda social, que agora passa a ser produzida com maior definição. As empresas se espelham no modelo internacional avançado e querem aplicar a nova onda motivacional e a demanda expertise sobre o assunto. O avanço do ensino público e as novas tecnologias de ensino pedem um novo tratamento para o fracasso escolar, e a divulgação dos tratamentos exitosos para o sofrimento psíquico inspira profissionais a exercê-los na clínica e a responder à demanda da própria sociedade.

Assim, chegamos ao final da década de 50 com massa crítica suficiente para reivindicar 
5 De acordo com Soares, a Portaria no 272, de 13 abril de 1946, do Ministério de Educação e Saúde, no seu artigo 1으, coloca a Psicologia no rol das especializações que devem ser realizadas pelas faculdades de Filosofia, e regulamenta a atribuição do diploma de especialista da seguinte forma: "1) Psicólogo: aprovado nos três primeiros anos do curso de Filosofia, bem como em cursos de Biologia, Fisiologia, Antropologia, Estatística e em cursos especializados de Psicologia. Finalmente, estágio em serviços psicológicos, a juízo dos professores da seção" (1979, p. 20). Em maio, a portaria é modificada, e passa a incluir o diploma de especialização em

Psicologia Educacional, com exigência de aprovação nos três primeiros anos de

Pedagogia e aprovação em cursos de

Psicologia da Criança e do Adolescente, em

Psicologia do Anormal, em Psicologia da

Personalidade e estágio em serviços de Psicologia

Aplicada e frequência

a seminário de método

e pesquisa psicológica.

Em 25 de outubro de

1949, o Ministério da

Guerra publica a Portaria

$\mathrm{n}^{\circ}$ 171, com "instruções

para o funcionamento do

Curso de Classificação de

Pessoal, incluindo noções de Psicologia Normal

e Patológica baseadas em métodos e objetivos da Psicologia que versavam sobre memória, raciocínio, imaginação, volição e Psicologia dos chefes militares" (p.20).

$\mathrm{O}$ autor ressalta que

a importância dessa portaria, considerando as portarias anteriormente mencionadas, outorga o diploma de psicólogo. A partir dessa data, passamos a ter reconhecido esse profissional pelo Estado brasileiro. a regulamentação da profissão de psicólogo. Aqui temos um fato curioso que está relacionado ao que discutimos anteriormente sobre as profissões imperiais. As profissões são construídas histórica e socialmente; não necessitam de regulamentação oficial para garantir a sua existência. Muitas foram as profissões/ocupações, hoje plenamente reconhecidas, que seguiram a trajetória do reconhecimento social e que são respeitadas mesmo não sendo regulamentadas. Muitas são as profissões universitárias que não têm regulamentação própria, e as profissões não universitárias, denominadas por Coelho ocupações, não deixam de ter importância a despeito de não serem regulamentadas. É o caso das parteiras, que, ainda hoje, em cidades com poucos médicos, são profissionais requisitadas. Há dúvidas sobre o prestígio da parteira em comunidades com pouco acesso? Em 1984, passei uma temporada em uma pequena vila no Vale do Ribeira (uma das regiões mais pobres do Estado de São Paulo) encravada na Mata Atlântica e próxima da cidade de Iporanga. Conheci uma senhora, a parteira da vila, que me disse ter colocado a maior parte das crianças daquela região no mundo. Quando Ihe perguntei se havia perdido alguma, respondeu que jamais, e que, nos casos de parto difícil, mandava para o médico no pequeno hospital de Iporanga (uma hora por estrada precária de terra). Perguntada sobre como diagnosticar os casos difíceis, ela, com um sorriso maroto e competente, me disse: - A gente sabe, meu filho! O que me surpreendia era o prestígio dessa senhora naquela pequena localidade. Era a madrinha reconhecida por todos, adultos e crianças. É importante notar que o parto é um evento natural, e não uma doença, portanto, não é necessário diagnosticar o parto. Nascemos assim desde sempre, e nossa espécie tem mais de 200 mil anos. Entretanto, no Brasil, médicos buscam proibir uma pessoa que não seja médica de realizar partos, e foi o que fizeram, buscando a proibição do Curso
Superior para Formação de Obstetrizes, na USP-Leste. Por sua vez, essa nova profissão, que foi incorporada pela Enfermagem, quer tirar do vernáculo o termo parteira, e, quando vencer a resistência médica, poderá seguir o mesmo caminho, buscando criminalizar a prática das parteiras sem curso superior.

As profissões adquirem prestígio e são valorizadas de acordo com a necessidade social de suas funções e conhecimentos. Assim ocorreu com a Psicologia. Quando regulamentada, em 1962, já era uma profissão ${ }^{5}$.

Entretanto, cabe perguntar: por que a Psicologia logrou sua regulamentação? A pergunta não é descabida, ainda mais considerando que o Brasil foi um dos pioneiros na regulamentação dessa profissão. Uma hipótese para a precoce regulamentação da Psicologia talvez seja a tradição cartorialista de nossa burocracia estatal e uma certa dose de oportunismo dos psicólogos interessados no estabelecimento de um mercado e de espaço institucional para a profissão. É preciso convir que a Psicologia, nos idos de 1950, não podia se configurar como uma atividade considerada indispensável pela população que utilizava serviços de saúde ou pelas famílias cujos filhos enfrentavam problemas escolares, mas, do ponto de vista acadêmico, estava em franco desenvolvimento em nossas principais universidades, e o campo industrial logo cedo (emulando o que ocorria nas industrias americanas) descobriu a sua relevância na seleção, na avaliação de desempenho e nos trabalhos motivacionais com os trabalhadores (Antunes, 1999). Mas é fato que a Psicologia não era uma profissão conhecida pelo grande público.

Outro aspecto sobre a regulamentação é que, além da fragilidade da profissão naquele momento, havia a fragilidade institucional brasileira. O País não representava, na época, um polo de importância mundial que exigisse 
garantias institucionais para a regulamentação de profissões. A Odontologia, por exemplo, teve seu Conselho Federal criado em 1964 (Lei n4324), e a regulamentação da profissão em 1966 (Lei $n^{\circ}$ 5081), e a Enfermagem teve seu Conselho Federal criado em 1973 (Lei $n^{\circ}$ 5905), mesmo ano da criação do CFP (a elaboração em lei se deu em 1971), e a regulamentação, em 1986 (Lei $n^{\circ}$ 7498). Notem que profissões estabelecidas e reconhecidas de longa data não careciam de documento legal para atestar o seu mérito, e, no caso das duas citadas, a criação dos Conselhos foi anterior ao documento legal que as regulamentou. A Medicina teve um decreto imperial que a certificou no reinado de D. Pedro II e outro em 1937, e com esse último funciona até hoje. Um dos argumentos para a Lei do Ato Médico é a suposta falta de regulamentação; verdade, por um lado, na medida em que a antiga legislação não atende as demandas atuais da profissão, e, por outro, engodo, considerando que a Lei do Ato Médico busca legislar limites para as demais profissões da saúde.

O período que se inaugura depois da Segunda Grande Guerra, com intensa onda de democratização em todo o mundo e que coincide com a queda do Estado Novo getulista aqui no Brasil, permitiu entre nós a busca de reorganização institucional, e isso gerou a pressão para regulamentar várias profissões, como mencionamos acima.

No caso da Psicologia, a busca de regulamentação é também a busca de reconhecimento da profissão através do estatuto legal, uma estratégia que partia de cima para baixo, mas que acabou logrando um bom resultado.

Os depoimentos foram tirados do artigo 30 anos de regulamentação publicado na Revista Psicologia Ciência e Profissão de 1992. fornecidos a essa mesma publicação do CFP, Revista Ciência e Profissão, em 1992, em comemoração aos 30 anos da regulamentação da nossa profissão:

Marcos Antônio Chaves (Presidente do CFP na época dessa publicação) ${ }^{6}$ :

“... Mas a primeira organização representativa da profissão surgiu em 1954, com a criação da Associação Brasileira dos Psicólogos, com sede no Rio de Janeiro.

Surgiram, então, as primeiras publicações especializadas para o pessoal que trabalhava na profissão e estudantes. A primeira dessas publicações foi a revista Arquivo Brasileiro de Psicotécnica.

Essa associação elaborou, também, um anteprojeto de lei objetivando a regulamentação da profissão de psicologista, como na época era denominada a profissão. Havia, naquela época, um movimento no sentido de oficializar a profissão. Os profissionais, através desse movimento organizado, pretendiam traçar os limites de atuação, definindo os espaços específicos da Psicologia, e eram realizadas, com esse objetivo, reuniões simultâneas em diversos Estados".

Segundo Antônio Marcos, esse movimento culminou na formalização da Lei n ${ }^{\circ} 4.119$, que regulamentou a profissão no dia 27 de agosto de 1962. "Essa regulamentação veio encontrar a grande maioria dos psicólogos atuando em instituições. O trabalho em consultórios era bem restrito".

Oswaldo de Barros Santos (psicólogo paulista):

“Os anos 50 foram fundamentais para a regulamentação da profissão. Precisava-se com urgência de um organismo que fiscalizasse a prática da Psicologia, naquela época exercida, também, por muitos charlatões.

... Esse organismo, fruto de um esforço conjunto de profissionais de São Paulo, Minas, Rio de Janeiro, Rio Grande do Sul e Pernambuco, principalmente, surgiu no final daquela década.

Foi o Sindicato dos Psicólogos do Estado de São Paulo que iniciou, imediatamente, um trabalho de elaboração de um projeto de lei que, em 1962, veio se transformar na Lei ${ }^{\circ}$ 4.119 . 
Mas, antes que isso se tornasse uma realidade muito esforço, muito trabalho teve de ser realizado, principalmente o de convencimento dos Deputados, que não entendiam direito o que estávamos querendo. Confundiam a Psicologia com a Medicina".

Segundo o psicólogo, um grande número de modificações foi apresentado ao projeto, mas, graças à atuação permanente dos grandes professores das áreas de ciências sociais, Pedagogia e Filosofia, essas foram aos poucos sendo removidas.

Afirma Oswaldo Santos: "Conseguimos aprovar o projeto tal qual queríamos graças também ao Deputado Clóvis Stenzel, líder do governo na Câmara. Ele apresentou o projeto e o defendeu de todas as formas possíveis contra todos os tipos de resistência.

Poucos países naquela época dispunham de uma lei de regulamentação da Psicologia, e, para entrar nesse restrito grupo, foram necessários, só na tramitação do projeto, mais de três anos. Para se ter uma ideia da dificuldade a tramitação passou pelos governos de Juscelino Kubitscheck e Jânio Quadros e o projeto foi aprovado no de João Goulart. Os gaúchos sempre deram muita força".

Halley Bessa (psicólogo e psiquiatra mineiro):

"Anteriormente à promulgação da Lei ${ }^{\circ}$ 4.119, de 1962, a profissão de psicólogo vinha sendo exercida no Brasil por profissionais formados no exterior e por mais aqueles que, tendo realizado aqui cursos superiores, especialmente nas áreas da educação, da Filosofia e das ciências sociais, passavam a trabalhar em instituições onde aplicavam a Psicologia, complementando, dessa forma, no próprio trabalho, a sua formação acadêmica (Angelini) ${ }^{7}$.

Ficou reservado aos educadores o maior interesse. Lembrem-se de Lourenço Filho, Noemi Silveira Rufolfer e Helena Antipoff não apenas na educação mas também nas áreas do trabalho e da clínica.

Na inexistência da legislação específica que oferecesse a garantia e a segurança para o exercício independentemente da profissão que a lei de 1962 veio trazer, aqueles que se dedicavam à Psicologia o faziam através do magistério ou de alguma instituição educacional, assistencial ou hospitalar, ou mesmo em serviço de seleção, treinamento e orientação profissional (SENAI, SENAC,
ISOPT, SOSP e outros congêneres (conforme Angelini).

Entidades de Psicologia, como a Associação Brasileira de Psicologia, a Associação Brasileira de Psicologia Aplicada, a Sociedade de Psicologia de São Paulo e a Sociedade Mineira de Psicologia, isolada, conjunta ou solidariamente se empenharam junto aos poderes Executivo e Legislativo para procurar demonstrar que o desenvolvimento social e as aplicações da Psicologia que já se verificavam na época (50/60) estavam a exigir que se viesse a estabelecer a formação regular de psicólogos e a regulamentar (os futuros Conselhos) e suas atividades profissionais para todo o território nacional (ainda Angelini).

Com esse apoio e com a regulamentação legal (das Leis $n^{\circ} 4.119 / 62$ e $n^{\circ}$ 5.766/71), os que já exerciam atividades de Psicologia nas escolas e instituições, aproveitando a oportunidade (art. 21 da lei básica), puderam regularizar seu exercício, em um primeiro momento, registrando-se no antigo MEC, e depois, inscrevendo-se no respectivo Conselho Regional".

Por fim, a professora Regina Helena de Souza Campos, importante historiadora da Psicologia, mas que é de geração posterior aos pioneiros mencionados, foi convidada a comentar os 30 anos da regulamentação nesta edição da Ciência e Profissão:

“A regulamentação da profissão de psicólogo no Brasil, em 1962, ao definir não só as condições de formação mas também as áreas de domínio prático que viriam a ser consideradas privativas do profissional, marca o reconhecimento da existência de um lugar para o psicólogo na divisão social e técnica do trabalho. Não que não existissem entre nós, no período anterior à lei, profissionais praticando a Psicologia nas mais diversas instituições.

Muito antes da regulamentação da profissão, a Psicologia existiu como um domínio de saberes e técnicas que visavam ao conhecimento e à intervenção sobre a ação e a reflexão humanas. Existia, sobretudo, como uma esperança: a de que o saber científico e o domínio de uma tecnologia de análise e de manipulação da natureza humana viessem a contribuir para a resolução de problemas e de conflitos de natureza psicológica observados de modo crescente na sociedade contemporânea. 
A regulamentação da profissão veio referendar e delimitar, simbolicamente, a existência desse domínio técnico-científico. A definição legal é, portanto, um registro histórico dos dois movimentos que the deram origem: o movimento social de progressiva racionalização das funções a serem desempenhadas nas modernas sociedades industriais, entre as quais se insere o conjunto de funções atribuídas ao psicólogo, e o movimento dos profissionais já engajados na prática em busca do reconhecimento e de segurança para exercer a profissão.

A comemoração destes 30 anos (1992) de existência oficial da profissão provoca a reflexão sobre o sentido dos saberes e práticas que têm guiado a atuação da comunidade dos psicólogos ao longo destas três últimas décadas no Brasil. Como participante do movimento de implantação da profissão nesse período, primeiro como estudante, entre 1969 e 1974, e depois como professora, pesquisadora e orientadora de trabalhos de extensão no Curso de Psicologia da UFMG, creio que posso dar um depoimento pessoal sobre nossa evolução".

Os depoimentos corroboram o fato de que a regulamentação parte do grupo de profissionais e acadêmicos da Psicologia que buscam o reconhecimento da corporação e também a elaboração de um protocolo que permitisse a formação autônoma, em cursos independentes e específicos de Psicologia, um grupo de profissionais que buscavam a construção da identidade profissional de uma categoria em formação. Os pedagogos não obtiveram a regulamentação da profissão até hoje, mas, antes de 1962, eram formados em cursos específicos que lhes garantiam autonomia. Os psicólogos eram formados em outros cursos citados pelos depoentes, e a Psicologia era exercida pelo profissional que por ela se interessasse e se sentisse capaz ou fosse, pelas circunstâncias, compelido a exercê-la. A busca de garantias e de proteção corporativa e a constituição de um campo de distinção que seria produzido com o reconhecimento social da profissão (aquele que identificamos quando informamos a um interlocutor que somos psicólogos) e, por fim, a autonomia acadêmica (deixar de ser apêndice de outras disciplinas) são os móveis centrais da busca da regulamentação.

Surpreende o fato de a lei da regulamentação - a n 4119/62 - ter sido aprovada com o mencionado desconhecimento da prática da Psicologia pelo legislador e dada a resistência, principalmente dos médicos, ao reconhecimento e à autonomia de um saber que, em parte, consideravam do seu campo (particularmente a clínica psicológica). Vale considerar que a Lei n 4119/62, como vimos pelo depoimento de Oswaldo de Barros, foi considerada uma grande e ampla vitória para a categoria. A profissão de psicólogo passou a existir legalmente a partir dessa data!

\section{A profissão 50 anos depois}

A estratégia do grupo que, no final dos anos de 50, lutou pelo reconhecimento da Psicologia como profissão regulamentada mostrou-se correta, independentemente dos motivos de ordem coorporativa ou do interesse de produzir reserva de mercado, ou, ainda, de garantir a melhor qualificação para o profissional que resolvesse optar por esse caminho profissional. A História tem muitos outros determinantes que vão além dos interesses coorporativos. O desenvolvimento daquilo que conhecemos hoje como capitalismo tardio, a fase atual do capitalismo, que estava sendo gestada exatamente na época em que o grupo de psicólogos estava discutindo a regulamentação da Psicologia, é um fator importante para o sucesso da profissão. A chamada Terceira Revolução Industrial mudou consideravelmente o nosso modo de vida, e o aumento da demanda pelo setor de serviços 
mudou a feição das grandes cidades (e depois das pequenas também). O novo estilo de vida proporcionado pelas novas relações de trabalho exacerbou o individualismo já presente no estilo de vida do pós-guerra, e, ao mesmo tempo, com o crescimento exponencial da tecnologia da informação, propiciou a troca de um campo de valores tradicionais para o da mudança constante como símbolo da modernidade. Os processos subjetivos passaram a ser pautados pelos meios de comunicação e transformaram-se em mercado de consumo nas mais diferentes formas: dos talk-shows aos programas estilo big-brother, dos livros de autoajuda aos encontros de grupos motivacionais, das religiões meditativas às práticas de terapias alternativas, enfim, da cotidianização da contracultura e da institucionalização da busca interior, colocaram a subjetividade na ordem do dia, e a Psicologia era o campo científico e profissional mais qualificado para atuar e para falar sobre esse assunto. Assim, nossos pioneiros souberam aproveitar o zeitgeist que estava ainda em formação e anteciparam-se à onda subjetivista que perdura até nossos dias.

Uma das políticas centrais do período de ditadura militar foi a de ampliar rapidamente o ingresso nas universidades, e, na falta de vagas públicas, incentivaram o setor privado a assumir o déficit de vagas do ensino universitário. Vivemos, na década de 70, logo após a promulgação da Lei da Reforma Universitária, um boom de crescimento do setor privado na educação superior, e a Psicologia foi um dos cursos presentes na abertura das novas IES. O empresário da educação, que buscava mais o investimento que um programa científico, não brincava em serviço, e percebeu que, entre os cursos mais procurados, estaria a Psicologia. A demanda de vagas dizia respeito ao Direito, à Pedagogia, à Administração de Empresas e à Psicologia; a Engenharia e a Medicina permaneciam controladas, principalmente a Medicina, como é até hoje. Além disso, muitas outras profissões foram criadas nesse período, e algumas graças ao faro mercadológico dos empresários da educação.

Lembrando que a História não tem caráter maniqueísta, alguns dos cursos de Psicologia privados que haviam sido abertos nesse período começaram de forma mercantil e foram mudando com o seu desenvolvimento, e transformaram-se mais tarde em cursos de qualidade. Outros permaneceram formando profissionais sem capacidade para ir além de uma reprodução técnica da Psicologia, e outros acabaram sendo inovadores. É preciso salientar que as universidades públicas, as universidades católicas e as comunitárias foram as guardiãs da qualidade do ensino e da pesquisa, e o primeiro momento de abertura indiscriminada foi aos poucos sendo controlado. Em geral, os jovens professores contratados pelas escolas privadas eram oriundos de cursos de boa qualidade, e lutavam para levar e garantir essa qualidade nas IES que os contratavam. Mas o fato que prepondera é que aumentou consideravelmente o número de psicólogos formados a partir de 1970.

Seria difícil imaginar que esse fenômeno ocorreria quando, entre 1955 e 1962, se forjou a regulamentação da Psicologia, mas, quando ocorreu, a Psicologia estava preparada para enfrentá-lo. Abria-se curso na área porque havia demanda e porque a profissão era regulamentada. Os psicólogos formados esgarçavam o mercado de trabalho e construíam um know-how em muitas áreas novas, garantindo a expansão da profissão, e transformavam a Psicologia em uma real 
oportunidade profissional. Os jovens ávidos por conhecer os mistérios da alma, impulsionados pela reconstrução de valores de um mundo que descobria a subjetividade, embarcavam nessa aventura com gosto.

O fato é que o Brasil se transformou no país com um número expressivo de psicólogos, e pode representar um dos maiores do Planeta ou, ao menos, do ocidente! Temos, atualmente, no ano corrente 2012, 216 mil psicólogos inscritos e ativos no Sistema Conselhos de Psicologia, e há estimativa de que um número considerável (talvez mais de 100 mil!) tenha se formado e não exerça a profissão.

Aqui reside nossa força e nosso problema, e a categoria precisa enfrentar esse dilema para se firmar definitivamente como uma profissão madura como condição para enfrentar os próximos 50 anos. Assim, cabe um balanço do esforço realizado durante estes 50 anos e, particularmente, após a criação do Conselho Federal e dos Regionais de Psicologia, no ano 1971.

A criação do Conselho profissional, como ocorreu com as demais profissões regulamentadas, organizou a intervenção social da profissão. Por um lado, ajudou a nortear a maneira como os profissionais formados iam ocupando o mercado de trabalho. Do ponto de vista da clínica psicológica exercida nos consultórios, o Código de Ética normatizava a conduta e oferecia garantias aos profissionais (valorizando sua prática) e aos usuários dos serviços, estabelecendo um padrão a ser observado. Ao mesmo tempo, o crescimento advindo do chamado milagre econômico da ditadura organizou o mercado interno (particularmente a partir do fechamento das importações e da reserva de mercado) e abriu vagas na indústria, no comércio e na área de serviços. Constitui-se um polo consumidor no Brasil e consolida-se o polo industrial. Os psicólogos foram chamados a organizar a gestão de pessoas, as seleções de profissionais, a realizar a avaliação de desempenho, etc. Cresceu de maneira significativa o polo organizacional, e, depois do consultório, esse passou a ser o maior setor de ocupação dos psicólogos no período.

As demais ocupações dependiam da ação do poder público e de maior organização do País, que teve seu crescimento econômico proveniente do processo de redemocratização, em 1946, com o fim do Estado Novo, com a industrialização, a partir do Governo JK (o famoso 50 anos em 5) e o desenvolvimento da década de 70, com o aporte de capital estrangeiro e a internacionalização de nossa economia, que tiveram como contrapartida melhor organização dos serviços públicos. O aumento do número de vagas no sistema geral de ensino, a organização do atendimento à saúde pública, o aparecimento das organizações não governamentais (ONGs), e, mais tardiamente, a organização da assistência social no Brasil abriram campo de trabalho para os psicólogos. O setor público passou a ser um grande empregador nos três níveis: municipal, estadual e federal. Esse processo culmina com a promulgação da Constituição de 1988 e a institucionalização do Estado de Direito e da ordem democrática, pondo fim ao período arbitrário da ditadura militar. A partir desse momento, e com o País iniciando uma nova fase de sua institucionalização, a presença do ator social na cena política pública garantiu maior espaço de participação popular nas reivindicações sociais. Em consequência, tivemos o aumento da demanda de serviços prestados aos cidadãos brasileiros e maior 
demanda profissional para as profissões das áreas da saúde, educação, serviço social, segurança, obras públicas, etc. A Psicologia faz parte do rol das profissões demandadas e passa a ser reconhecida como profissão relevante em vários desses segmentos.

Publicados em 1992 e 1994, dois importantes diagnósticos das ocupações dos psicólogos em sua profissão - Psicólogo brasileiro: construção de novos espaços e Psicólogo brasileiro: práticas emergentes e desafio para a formação - ambos realizados pelo Conselho Federal de Psicologia, apontam o que seria o estado da arte e as perspectivas para a profissão na avaliação de eminentes figuras do mundo acadêmico e que também estavam presentes na entidade que buscava conhecer melhor a categoria 30 anos depois da promulgação da lei que havia regulamentado a profissão. Nas duas publicações, há uma preocupação com o que está por vir do ponto de vista de novas ocupações, mas os títulos dos capítulos demonstram o gabarito profissional existente: o campo clínico, educacional, organizacional, a Psicologia social e a preocupação com a formação. Em 1995, com o recadastramento dos psicólogos pelo Sistema Conselhos de Psicologia, o CRP da $6^{\underline{a}}$ Região, que compreendia, na época, os Estados de São Paulo, Mato Grosso e Mato Grosso do Sul (que congrega mais de $40 \%$ dos psicólogos brasileiros), publica seu relatório estatístico (produzido pela Fundação SEADE), que revelou que $70,5 \%$ dos psicólogos cadastrados atuavam na profissão. Destes, $54 \%$ declaram atuar em saúde, 18\%, em educação, 13\%, em organizacional e trabalho, e $5 \%$, na área social. Por outro lado, $47 \%$ declararam trabalhar como autônomos, $29,6 \%$ são contratados pela CLT, e $12 \%$ são funcionários públicos. Não foi perguntado se os autônomos exerciam sua atividade em seus próprios consultórios, mas é o mais provável.
Temos massa considerável de psicólogos que exercem a clínica como profissionais liberais. Essas informações interessam aos profissionais, porque foram produzidas de forma censitária e em uma região com grande concentração de psicólogos brasileiros.

Somente em 2004 teremos uma pesquisa, realizada pelo CFP (IBOP), com amostragem nacional. Essa pesquisa procurou replicar estudos anteriores realizados pelo próprio CFP, mas sem rigor maior na amostragem. Nela, 55\% declaram realizar atendimento clínico individual ou em grupo, 17\% trabalham na área organizacional/institucional, 11\%, em educação, 11\%, em políticas públicas de saúde, segurança e educação, 5\%, na docência e na pesquisa em Psicologia, e 1\%, na área jurídica. Quando consultados sobre o local em que exerce o trabalho, $41 \%$ declara exercêla no consultório particular. Considerem que esses psicólogos representam 84\% daqueles que exercem a profissão exclusivamente ou junto a outra atividade (26\%).

A pesquisa realizada pelo grupo da ANPEPP (Associação Nacional de Pesquisa e Programas em Psicologia) e publicada com a organização de Bastos e Godim (2010), aponta outro fator digno de nota. Para Godim, Luna, Souza, Sobral e Lima,

... Ficou evidenciada, na pesquisa, a tensão entre a identidade do psicólogo apoiada em um modelo clínico de atendimento individual, presente na formação e no imaginário social, e as novas demandas de uma identidade do psicólogo mais sensível à sua responsabilidade social em assegurar o bem-estar de coletividades... Apesar das inúmeras áreas de atuação possíveis para o psicólogo, os resultados sinalizam haver uma identidade homogênea, todavia, essa identidade requer ajustes, dada a multiplicidade teórica adotada pelo psicólogo, a área geográfica em que atua e a expansão da experiência profissional adquirida (dimensões históricas e social) (2010, p. 244) 
Desde as primeiras análises realizadas na época em que a profissão comemorava seus 30 anos de regulamentação e a pesquisa realizada pelo grupo de Psicologia Organizacional e do Trabalho da ANPEP, nota-se uma evidente evolução do perfil da profissão, apesar de não ter ocorrido uma transformação qualitativa no sentido de alterar radicalmente o seu perfil. Mas podemos afirmar que a profissão vai perdendo seu caráter liberal e que o consultório particular como local preferencial para o trabalho do psicólogo vai perdendo lugar para outros locais de atuação. $\mathrm{Na}$ realidade, não perde sua importância, ganha a sua dimensão real com a maior inserção dos psicólogos no mercado de trabalho e com maior reconhecimento da profissão.

A avaliação de Gondim e colegas sobre a identidade dos psicólogos é correta e está baseada na forma como a profissão desenvolveu sua relação com os seus usuários e nas condições materiais concretas que o momento histórico propiciava. A clínica, indubitavelmente, é o principal atrativo da profissão e marca nossa identidade profissional, mas a alternativa liberal do consultório particular não é a melhor saída, do ponto de vista da absorção da força de trabalho. Essa afirmativa, evidentemente, serve para o Brasil de hoje e do período de desenvolvimento da profissão na sua fase regulamentada. Vivemos em um país sabidamente de profundas diferenças sociais, e ainda hoje temos mais de 20 milhões de pessoas que vivem abaixo da linha de pobreza, e a maioria das famílias é pobre.

Em 2008/2009, de acordo com pesquisa do IBGE (Pesquisa de Orçamento Familiar 2010), $60,6 \%$ das famílias brasileiras tinham renda mensal até $\mathrm{R} \$ 1.245,00$ (de uma base de 58 milhões de famílias); as famílias ricas, com rendimento familiar acima de $\mathrm{R} \$ 10.375,00$, representavam 3,8\%. Essa realidade não se altera radicalmente quando se analisa a curva do desenvolvimento de 1962 (ano da regulamentação) a 2010. Conclusão óbvia: para $60 \%$ das famílias, era impossível o acesso ao serviço privado prestado pelos psicólogos, e somente a partir do patamar considerado rico, amplamente minoritário, o psicólogo clínico encontraria mercado para a sua profissão. Se fizermos uma conta maluca, considerando três membros por família, teríamos menos de 30 possíveis clientes per capita para o número de psicólogos existentes no País atualmente. Como não atendemos $100 \%$ da população, nota-se que a conta não fecha. O consultório particular é uma alternativa legítima de trabalho para qualquer psicólogo, mas não é viável para toda a categoria. Os que optarem por essa via de trabalho irão correr o risco típico da livre iniciativa.

A profissão, hoje amplamente reconhecida, requer uma alternativa que garanta sua inserção profissional de forma duradoura e segura. Do ponto de vista da sua vocação clínica, considerando a identidade profissional como mencionada por Gondim et al. (2010), o psicólogo deve se dispor a atender os $96,2 \%$ das famílias sem acesso aos seus serviços privados, e isso somente pode ocorrer por meio de políticas públicas. O Sistema Único de Saúde, através da Atenção Básica, Saúde da Família, serviços ambulatoriais, CAPS, etc., e do serviço de saúde complementar são as alternativas que garantem ao psicólogo exercer o que ele considera sua atividade central. Além disso, é preciso encontrar outras alternativas de exercício da profissão, e isso vem sendo paulatinamente construído ao longo destes 50 anos. Hoje são reais as possibilidades de trabalho para o psicólogo além do consultório particular. Cresce a demanda nos serviços públicos de saúde. Somente nos CAPS, são mais de 50 mil profissionais (das várias áreas 
da saúde) contratados em todo o Brasil, e esse número vai crescer.

A Política Nacional de Assistência Social (PNAS) exige que nas unidades básicas da assistência social (CRAS - Centros de Referência da Assistência Social) sejam contratados ao menos um assistente social e um psicólogo (que não deverá exercer atividade clínica) $^{8}$. Quando a rede estiver instalada em todo o País, teremos um número expressivo de psicólogos contratados, equiparável ao dos CAPS. Estamos falando de 20, 30 mil psicólogos somente nesses tipos de serviços e equipamentos, quando toda a rede estiver instalada (talvez em 10 anos). Ainda temos a rede de Atenção Básica à Saúde, os Centros de Referência da Saúde do Trabalhador, os hospitais públicos e privados, os ambulatórios, o psicólogo no sistema Judiciário, no trânsito, no esporte, nas comunicações, as ONGs, e ainda mantemos os tradicionais setores da educação e das organizações.

A perspectiva futura da profissão é promissora, e há real garantia de mercado de trabalho para o psicólogo no momento atual e no futuro.

É preciso considerar que o caminho trilhado pela profissão nestes 50 anos, penoso algumas vezes, não surgiu espontaneamente e não foi obra do acaso. Além da luta cotidiana de cada psicólogo no afã de buscar a melhor condição de trabalho para si mesmo, temos que valorizar o empenho daqueles que, através do segmento organizado da categoria, pressionaram, propuseram, lutaram como puderam para garantir mais espaço de trabalho para os psicólogos brasileiros. Nestes anos todos, foram criadas inúmeras associações científicas, profissionais e sindicais que organizaram a produção do conhecimento científico, que revelaram as novidades e as possibilidades profissionais, que defenderam o espaço de trabalho do psicólogo.

Cabe ressaltar o papel do Fórum da Entidades Nacionais da Psicologia Brasileira - FENPB , que se transformou atualmente no principal organizador desse campo, e o do Conselho Federal de Psicologia, que, nestes últimos anos, vem trabalhando na construção de uma agenda para a profissão e fazendo esforços para mostrar a cara da Psicologia brasileira. Ressalto o trabalho realizado pelo CREPOP como particularmente destacado no estabelecimento de parâmetros para a profissão, e a realização da $1^{a}$ e da $2^{a}$ Mostra Nacional das Práticas em Psicologia, que representou (e representará) um marco para a área no Brasil. Foi a Mostra que permitiu vislumbrarmos a mudança de rumo dessa categoria e sua vontade de construir uma Psicologia com compromisso social. Essa é a real alternativa para a profissão e sua real possibilidade de se constituir como uma profissão de destaque e indispensável para a população brasileira. 


\section{Odair Furtado}

Doutorado em Psicologia pela Pontifícia Universidade Católica de São Paulo. Professor associado da Pontifícia Universidade Católica de São Paulo, São Paulo, SP - Brasil.

E-mail: odairfurtado@pucsp.br

Endereço para envio de correspondência:

Rua Doutor Homem de Melo 70, Perdizes, São Paulo - SP - Brasil. CEP: 05007-000 


\section{Referências}

Andrada e Silva, J. B. (1998). Projetos para o Brasil. São Paulo: Cia das Letras.

Amsden, A. H. (2009). A ascensão do "resto": os desafios ao ocidente de economias com industrialização tardia (R. M. dos Santos, trad.). São Paulo: UNESP.

Antunes, M. A. M. (1999). A psicologia no Brasil: leitura histórica sobre sua construção. São Paulo: EDUC/UNIMARCO.

Antunes, M. A. M. (Org.). (2004). História da psicologia no Brasil: primeiros ensaios. Rio de Janeiro: Eduerj.

Bastos, A. V. B., Godim, S. M. G. (Orgs.). (2010). O trabalho do psicólogo no Brasil. Porto Alegre: Artmed.

Bourdieu, P. (2007). A distinção: crítica social do julgamento (D. Kern \& G. J. F. Teixeira, trads.). São Paulo: EDUSP; Porto Alegre: Zouk.

30 anos de regulamentação (1992). Psicologia Ciência e Profissão, 12(2), 4-9.

Conselho Federal de Psicologia - CREPOP. Referências Técnicas para a atuação do(a) Psicólogo(a) no CRAS/SUAS. Recuperado em 13 de junho de 2012 de www.pol.org.br.

Coelho, E. C. (1999). As profissões imperiais: medicina, engenharia e advocacia no Rio de Janeiro 1822-1930. Rio de Janeiro: Record.

Foucault, M. (1980). O nascimento da clínica (2a ed., R. Machado, trad.). Rio de Janeiro: Forense/Universitária.

Furtado, O. (2011). Trabalho e solidariedade. São Paulo: Cortez.

Furtado, O. (2002). As dimensões subjetivas da realidade: uma discussão sobre a dicotomia entre a subjetividade e a objetividade no campo social. In O. Furtado \& F. GonzálezRey (Orgs.), Por uma epistemologia da subjetividade: um debate entre a teoria sócio-histórica e a teoria das representações sociais. São Paulo: Casa do Psicólogo.

Furtado, O., \& Svartman, B. P. (2009). Trabalho e alienação. In A. M. B. Bock \& M. G. M. Gonçalves. A dimensão subjetiva da realidade: uma leitura sócio-histórica. São Paulo: Cortez.
Recuperado em 18 de junho de 2012 de http://www. ibge.gov.br/home/estatistica/populacao/condicaodevida/ pof/2008_2009

Massimi, M. (1986). As origens da psicologia brasileira em obras do período colonial. In M. C. Guedes, História da psicologia. São Paulo: EDUC.

Massimi, M. (1990). História da Psicologia Brasileira: da época colonial até 1934. São Paulo: EPU.

Massimi, M. (1999). O lugar dos conhecimentos psicológicos na cultura luso-brasileira do século XVI ao século XVIII. In M. C. Guedes \& R. H. F. Campos, Estudos em história da psicologia. São Paulo: EDUC.

Paula, S. G. de. (Org.). (2001). Hipólito José da Costa. São Paulo: Editora 34

Pessoti, I. (1975). Dados para uma história de psicologia no Brasil. Psicologia, 1(1), 1-14

Pessotti, I. (1988). Notas para uma história da psicologia brasileira. In Conselho Federal de Psicologia. Quem é o psicólogo brasileiro? (pp.17-31) São Paulo: Edicon.

Política Nacional de Assistência Social - (PNAS) Aprovada pelo Conselho Nacional de Assistência Social por intermédio da Resolução no 145 (15/10/2004) e publicada no Diário Oficial da União em 28/10/2004.

Rocha, A. P. (Org.). (2001). José da Silva Lisboa, Visconde de Cairu. São Paulo: Editora 34.

Silva, M. R. B. (2010). Santa Casa de Misericórdia de São Paulo - saúde e assistência se tornam públicas (18751910). Vária História, 26, 44. Recuperado em 18 de junho, 2012 de http://www.scielo.br/scielo.php?pid=S0104$87752010000200004 \&$ script=sci_arttext\#nt01.

Soares, A. R. (1979). A psicologia no Brasil. Psicologia: Ciência e Profissão, 0. (Fac símile republicado em 2010 em Psicologia: Ciência e Profissão 30 anos - número especial).

Weffort, F. C. (2006). Formação do pensamento político brasileiro: ideias e personagens. São Paulo: Ática.

IBGE (2010)Pesquisa de Orçamentos Familiares 2008-2009. 